\title{
Applied Social and Communication Aspects of the Media Literacy Development in Future Specialists
}

\author{
Nataliia Haidur ${ }^{1}$, Vitalii Kornieiev ${ }^{2, *}$, Inha Pohrebniak ${ }^{3}$, Andriy Yatsenko ${ }^{4}$, Kateryna Horska $^{5}$ \& Eleonora Kryvka ${ }^{1}$ \\ ${ }^{1}$ Department of Social Communications, Private Higher Education Institution "Academician Stepan Demianchuk \\ International University of Economics and Humanities", Rivne, Ukraine \\ ${ }^{2}$ Department of Social Communications, Taras Shevchenko National University of Kyiv, Kyiv, Ukraine \\ ${ }^{3}$ Department of Journalism and New Media, Borys Hrinchenko University of Kyiv, Kyiv, Ukraine \\ ${ }^{4}$ Department of Mass Media Language, Ivan Franko National University of Lviv, Lviv, Ukraine \\ ${ }^{5}$ Department of Multimedia Thechnologies and Media Design, Taras Shevchenko National University of Kyiv, Kyiv, \\ Ukraine \\ *Correspondence: Department of Social Communications, Taras Shevchenko National University of Kyiv, 36/1, \\ Yuriy Ilyenko Str., Kyiv, 02000, Ukraine. E-mail: npu.institute@gmail.com
}

Received: December 9, 2021

Accepted: January 6, 2022 Online Published: January 17, 2022

doi:10.5430/jct.v11n1p174

URL: https://doi.org/10.5430/jct.v11n1p174

\begin{abstract}
The article examines the problems of applied social and communication aspects of the media literacy development in future teachers. The research involved such methods as sociological analysis, the reproductive method, the pedagogical experiment, testing, survey, as well as the method of dialectical research. The results of testing and surveying students showed the need to improve the applied social and communication aspects of the media literacy development in future specialists. The main ways to improve the media literacy development in future teachers were identified based on the results of testing and surveying students, namely: create special learning environments, involve students in project activities, organize student interactions with all participants in the learning process, etc. In the future, compliance with such recommendations will expand the dialogue needed between teachers and students, and increase awareness of future professionals features and skills of media literacy. As a result, it will allow future professionals to become aware of their responsibilities and obligations to society. In the future, compliance with such recommendations will expand the necessary dialogue between teachers and students, and increase future specialists' awareness of the features and skills of media literacy. As a result, it will allow future specialists to become aware of their responsibilities and obligations to society.
\end{abstract}

Keywords: media awareness, media education, media literacy of teachers

\section{Introduction}

\subsection{Research Topicality}

The analysis of modern pedagogical education shows a low level of media literacy skills of graduates majoring in Educational Sciences. Future teachers are not ready for processing new information, because universities do not have a clear system for the development of media awareness. Educators claim that the use of media literacy in the lessons allows involving additional data from various sources: reference books, audio materials, newspapers, visual aids, movies, etc.

According to Sharikov, Fazulyanova and Petrushkina (2006), the term "media literacy" is a calque of the English "media education", where the first part is an abbreviated form of "media communication".

Educators define the purpose of media literacy in terms of its interpretation. For example, Sharikov, Fazulyanova and Petrushkina (2006) believe that the goal of media literacy is media-communicative competence, and it should be interpreted not as the highest level of knowledge in various fields, but as "sufficient knowledge and skills to acquire, understand, create and exchange messages through communication". 
Based on these considerations, it can be assumed that the use of media in the lessons makes the learning process more effective, as information comes through various media channels and remains constantly available. That is, students are provided with a huge amount of new data that needs analysis, codification and generalization in order to use it for future learning (Akimov et al., 2021). Besides, obtaining new data enriches students' knowledge of various subjects, which must meet the requirements of the modern process of education and paradigm.

It should be noted that the continuous development and transformation of society on the basis of technological advances in some way prevent the government from adopting a specific media competence integrated into the education system. Therefore, there is a need for radical changes in the schemes of traditional education, which facilitate the necessary changes, guided by a consistent media system capable of meeting the requirements of the current context. On the other hand, signs of such changes are the actions of researchers, social groups, etc., despite the fact that certain events indicated the urgency of such changes, creating and implementing certain actions aimed at developing media skills in the population.

Maintaining media literacy skills is the focus of many socio-political and educational processes: it is the goal of media education. Educators should integrate media into the lessons and give time to discuss and reflect on media content to promote media literacy. This task is especially relevant if other agents of socialization do not provide (or cannot provide) this transfer of skills (for example, parents (Livingstone \& Sefton-Green, 2016)). To meet this challenge, several pilot projects and initiatives have been launched across Germany. However, media education is often optional, although it depends on teachers and their willingness to teach media literacy.

It should be added that the two exceptions are Thuringia and Bavaria, which enshrined media education in the school curriculum (Kühn \& Riesmeyer, 2021). In these two federal states, teachers are required to teach students how to handle the media properly (both technically and in terms of content). However, in order to successfully teach their students media literacy, they learn media literacy themselves.

\subsection{Aim}

The aim of the study is a detailed study of applied social and communication aspects of the media literacy development in future specialists.

Based on the above, we propose to identify the main objectives:

- study the issues of media literacy development as an important component inherent in the future teacher's professional competence;

- determining the level of theoretical and technological aspects of the development of this phenomenon in the modern education of teachers;

- identify the state of training of future teachers for teaching with the involvement of the media literacy development in future specialists;

- formulate proposals for improving media training of future teachers.

\section{Literature Review}

In studying the applied socio-communicative aspects of media literacy, future specialists took into account the position of the Media Literacy Association (AML), which offers a set of competencies of individual hierarchy in three levels of competence: accessibility and use of media, understanding and criticism, as well as communication and creative production (Area Moreira, Borrás Machado \& San Nicolás Santos, 2015). These competencies create an impact that goes beyond the acquisition of standards of conduct, but also covers such aspects as the individual's cognitive attitudes towards media and language development, the acquisition of values and criteria for ethical and democratic use of information, levels of codification, evaluation in communication, differentiation between the fantasy, artistic and subjective in a variety of media, which can be print, audio-visual or digital (Cuervo Sánchez \& Medrano Samaniego, 2014; Pérez-Escoda, 2017).

Under the conditions of this century, there is a continuous flow of information from various sources, which requires people to have a certain media literacy level, which allows future specialists to adequately interpret the forms and codes of various languages of current presentation of information, including texts, audiovisual and digital data, and together with them develop relevant skills and competencies, which consist in the ability to select, analyse and transform this information into knowledge with intercultural awareness of citizens (de Pablos Pons \& Ballesta Pagán, 2018). 
Taking into account the positions of foreign scholars, we got the opportunity to consider the ability of shaping thinking when obtaining and creating media products, understood as media and information literacy, which is associated with full awareness of individual and collective values, as well as responsibility for the product of ethical information and cultural dialogue (Jandrić, 2019).

The study of the theoretical background allows us to analyse the need to provide maximum flexibility for future teachers on how they can include the content of media literacy in their lesson plans. So, in order to be able to work in different educational institutions, it will be necessary to include a proposal to implicitly add media literacy as a measure of content standards for schools and institutions that are not necessarily open to media literacy (Mertala, 2020).

In general, current trends and importance of media literacy in basic and university education contributes to the analysis, understanding of messages transmitted by various means of communication, their reading and interpretation can be considered quite effective for making optimal decisions about the media literacy development in future teachers.

Various databases were used in the study: Scopus, Wos, Dialnet, Redalyc, Scielo, ResearchGate, RIDU (UPC Journals) and RevCom, which confirms the importance of information analysis of applied social and communication aspects of developing media literacy in future specialists.

Equally important is the early 2020 literature, when teachers and students around the world changed their distance learning system in just a few weeks after the Covid-19 pandemic. Based on this situation, we have had a unique opportunity to observe how theories of globalization of technology and education, which have been developed for decades, have undergone a reality test (Selwyn \& Jandric, 2020). So, according to UNESCO, it is not surprising that as of April 14, 2020, the activities of 1.6 billion (91.3\%) pupils and students in 188 countries were restricted because of COVID-19 (PARP, 2020).

\section{Methods and Materials}

\subsection{Research Procedure}

The applied social and communication aspects of the media literacy development in future specialists were studied on the basis of higher educational institutions of Ukraine, namely: Lviv Polytechnic National University and Franko National University of Lviv. These higher education institutions were chosen because these universities have a large number of students that will be able to provide objective results for research.

An important step in the study of this issue was to obtain permission from the heads of structural units of higher educational institutions, as the main respondents are students.

For our study of applied social and communication aspects of the media literacy development in future specialists in the course of practical training in higher educational institutions (HEIs) as a background for the readiness of future specialists, we used three levels proposed by Jones-Kellogg and Martin (2018) as evidence of knowledge of information to achieve a sufficient level, that is the level of "automation" of media literacy:

low level - the student clearly knows and understands the "planned" steps of the activities, can list the necessary sequence of steps and the opportunity of using particular means for the development of media literacy, but the student himself/herself never carried out this activity;

medium level - ("knows" - "is able to") begins with the fact that a student, guided by an instruction, carries out a particular technique (a series of techniques) of the educational activities a number of times, checking his/her steps with the instruction, which is in front of him/her or which he/she memorized. SIt will be more successful in this case. As a result, the student is able to implement the appropriate techniques for the development of media literacy, but he/she does that knowing how he is doing it, diverting his/her arbitrary attention to the technical aspects of the matter, and as a result, spending more time on it;

high level - level of mastery of media literacy techniques. The student, relying on the clearly understood phenomena of each of the following stages, does not think of them in the course of his/her activity, a technique or a series of techniques of educational activity, which are the basis of the exercise (assignment), are carried out automatically (task). This means that the technical side of the exercise does not distract the student, he/she does not think about it. The media literacy development is carried out at the level of skills: the student knows a technique. 


\subsection{Main Research Methods}

The research involved the method of sociological analysis, which helped to summarize the results of the study. The use of the reproductive method has contributed to the study of the media literacy development in students of higher educational institutions with the help of teachers who use a variety of exercises and assignments to improve students' mastery of tools and techniques of media literacy. The method of pedagogical experiment allowed initiating research on the media literacy development in future teachers. The use of testing methods and surveys ensured the most reliable research results. The dialectical method was used in considering the studied problems and determining the main directions of media literacy development in future teachers.

\subsection{Sampling}

In order to fulfil the objectives identified in the work, we used testing and survey methods. Testing and surveys were conducted with 80 students from Lviv Polytechnic National University majoring in Philology, and 110 students from Franko National University of Lviv majoring in Philology. The purpose of testing with students was to determine the state of their media literacy, and the survey - to improve the development of media literacy.

In general, the described procedure, methods and features of sampling were aimed at obtaining comprehensive information for the study.

\section{Results}

The rationale for any scientific research is to obtain reliable and complete information about an object, process or phenomenon. It was decided to test and survey the respondents to complete the study of applied social and communication aspects of the media literacy development in future specialists. Therefore, an anonymous survey of students of HEIs was conducted in order to identify the applied social and communication aspects of the media literacy development in future specialists and to determine the importance of applying media literacy knowledge obtained in HEIs while completing the assignments on this issue. The additional survey provided an opportunity to identify problematic issues of applied social and communication aspects of the media literacy development in future specialists in order to further improve them. Therefore, we propose to consider the questionnaire, which was provided for the survey, and to analyse the respondents' answers.

\section{Questionnaire to determine the future specialists' understanding of the importance of applied social and communication aspects of media literacy}

Please answer the suggested questions.

How did you learn that applied social and communication aspects of media literacy development can influence the skills of future specialists?

1. During the lessons

2. Teachers shared their own experience

3. From the Internet

4. From parents

5. Your option

Do you plan to develop media literacy skills?

1. I plan

2. I do not plan

3. I didn't think about it

Do you think that the media literacy development is part of the mandatory professional training of future teachers?

1. Yes

2. No

3. Partially

4. Your option

Does the media literacy development play an important role in the daily activities of future specialists? 
1. Yes

2. No

3. I don't know

4. Your option

What is the media literacy development (in your opinion)?

What difficulties did you face in terms of the applied social and communication aspects of media literacy development?

In your opinion, does the media literacy level in your university fully meet modern requirements?

1. Yes

2. No

3. Partially

4. Does not meet

5. There is a space for improvement

6. Your option

We ask you to provide a definition of "readiness for media literacy": your personal vision, interpretation (in short, no more than 5 lines).

Describe the concept of "media literacy" (in short, no more than 5 lines).

Is it necessary to develop skills of applied social and communication aspects of the media literacy development in future specialists?

1. Yes.

2. No.

Justify your point of view.

In the course of the research, a survey was conducted among students of such higher educational institutions as Lviv Polytechnic National University and Franko National University of Lviv. Therefore, we propose to consider the assessment of the media literacy level of 80 students of Lviv Polytechnic National University.

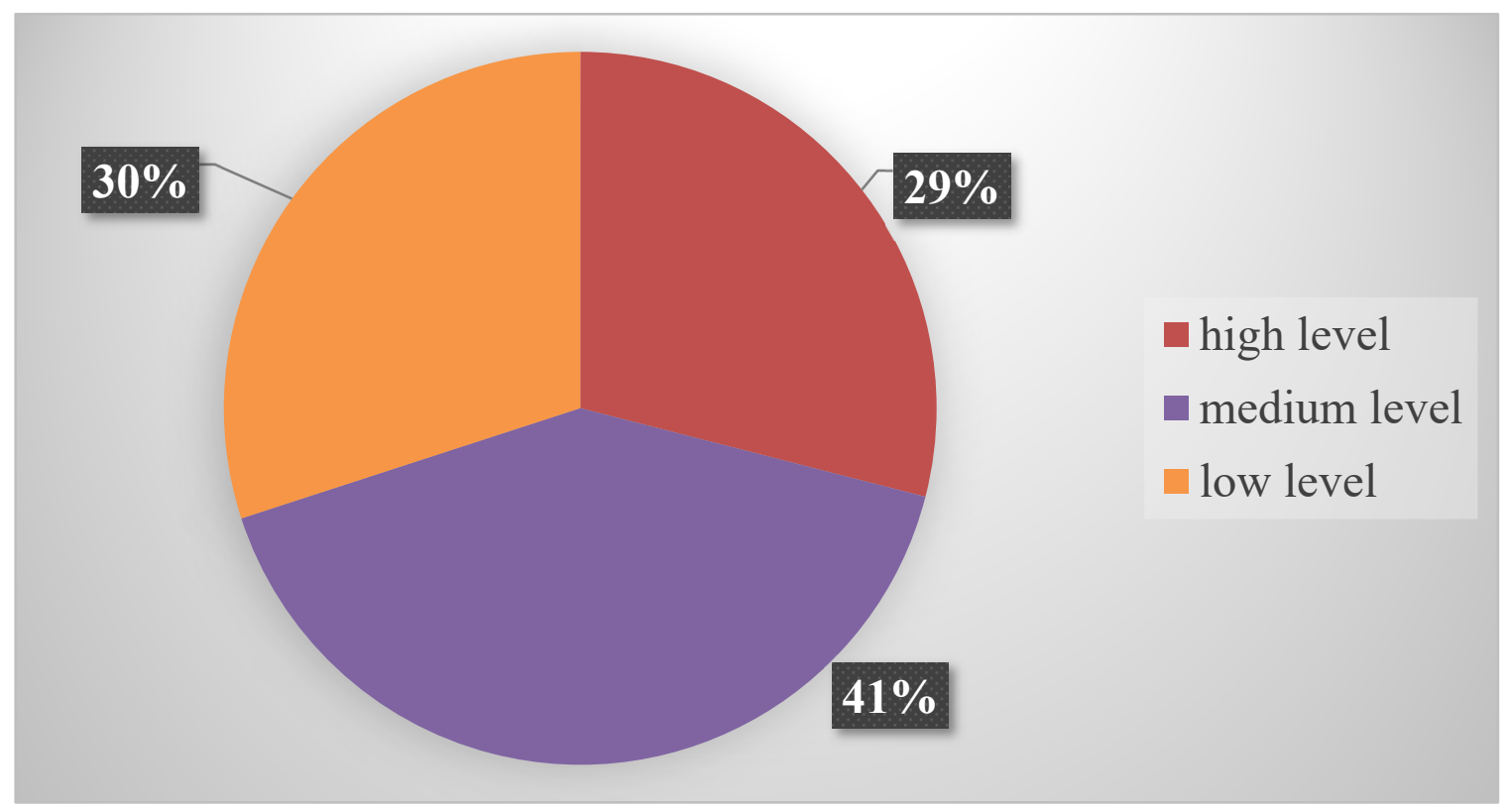

Figure 1. Assessment of the Media Literacy Level of Students of Lviv Polytechnic National University, \% 
The results showed that the high level is $29 \%$, which is quite a good indicator, given that $30 \%$ of students have an average level of awareness of the media literacy development. However, a significant percentage (41\%) are students with a low level of awareness. This indicates that Lviv Polytechnic National University should pay special attention to improving students' awareness of this issue.

The next step was the analysis of 110students of Franko National University of Lviv. We propose to consider the assessment of their level of awareness of the media literacy development in Figure 2.

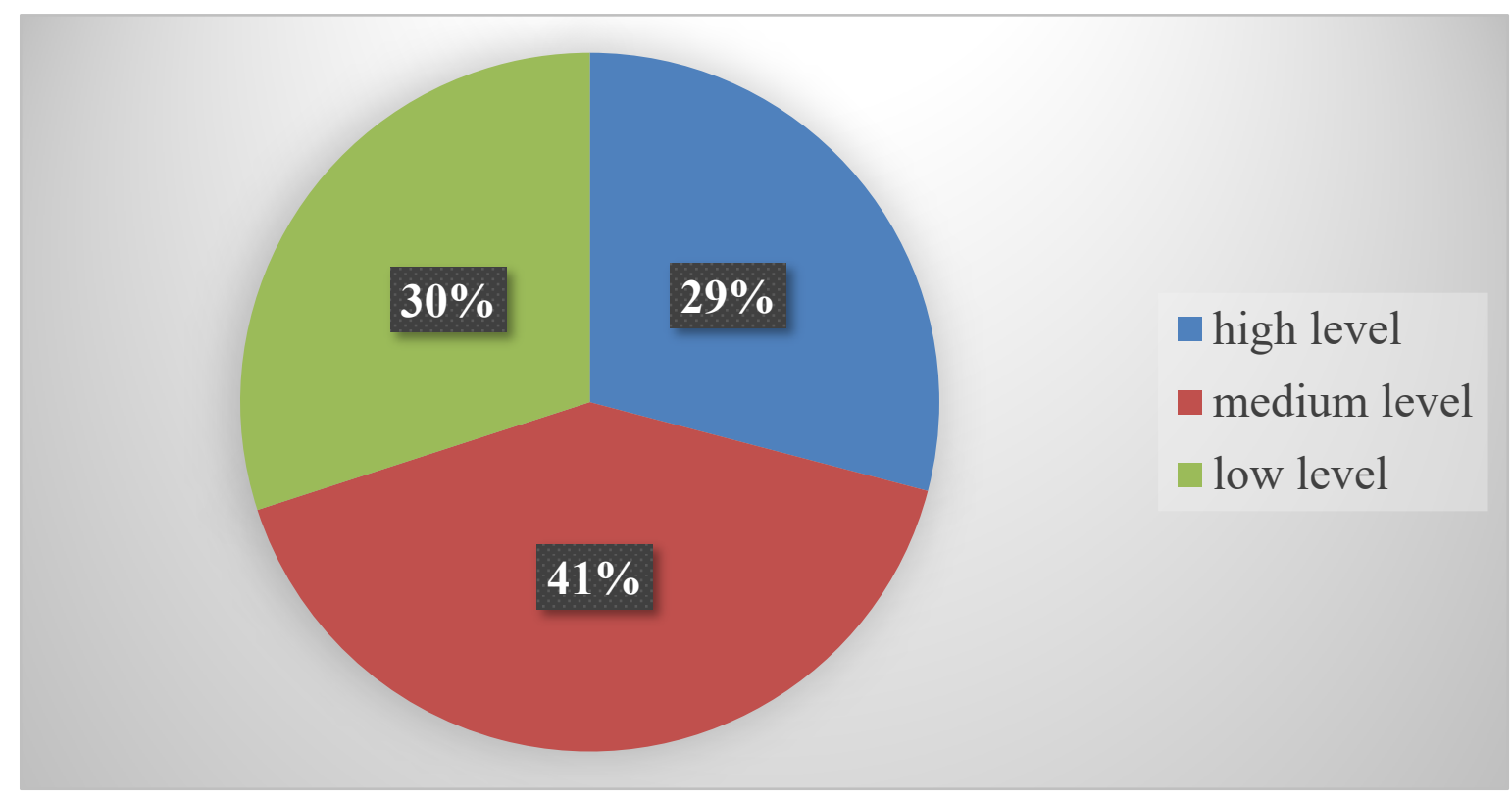

Figure 2. Assessment of the Media Literacy Level of Students of Franko National University of Lviv, \%

Analysing these indicators, we can see that there are very small changes in the indicators. That is, the high level is a minority $-29 \%$, the medium level is the largest share of respondents $(41 \%)$, and the low level of awareness is quite a significant proportion $(30 \%)$.

This trend indicates that only those students who show signs of interest in the media literacy development as a factor influencing the future specialists' activities have a medium and high levels of awareness. However, teachers who should have provided at least a medium level of awareness are not able to interest students with a low level of awareness, which would directly affect their professional activities in the future.

Based on the above results, we decided to compare the criteria that teachers use in their work in the selected universities to develop students' media literacy skills using a model of media education skills of future teachers developed by Semenova and Sotnikova (2021). The comparison is provided in Table 1.

So, we can see that in the media literacy development teachers of these universities use mostly similar factors in terms of presenting this issue. However, they also have differences, which directly depend on the university's level of interest to provide future specialists with the information on media literacy.

Besides, they noted that all respondents had a general idea of the importance of applied social and communication aspects of media literacy development, media literacy objectives and relevant knowledge, abilities and skills, but the level of their awareness is quite different.

It should be added that the assessment of the level of media literacy of university students was determined according to the following criteria: 1) media knowledge (knowledge necessary for the effective use of the media to address pedagogical issues of teaching); 2) media skills (the ability to find, process, create, understand and transmit input information through a system of media education); 3) value attitude to media education (the need for self-improvement in media education). 
Table 1. Model of the Media Education Skills Development in a Future Specialist

\begin{tabular}{|c|c|c|c|}
\hline & Factor & $\begin{array}{c}\text { Lviv Polytechnic } \\
\text { National } \\
\text { University }\end{array}$ & $\begin{array}{c}\text { Franko National } \\
\text { University of } \\
\text { Lviv }\end{array}$ \\
\hline \multirow{5}{*}{$\begin{array}{l}\frac{\tilde{e}}{0} \\
\frac{\pi}{\pi} \\
\frac{0}{2} \\
\frac{0}{2}\end{array}$} & student & + & + \\
\hline & problematic & - & - \\
\hline & communicative & + & + \\
\hline & competence-based & - & + \\
\hline & socio-cultural & + & + \\
\hline \multirow{13}{*}{$\frac{\varrho}{\frac{e}{2}}$} & scientific nature & + & + \\
\hline & connection of theory and practice & + & + \\
\hline & focus on the subject & + & + \\
\hline & learning process & + & + \\
\hline & interaction & - & + \\
\hline & information context & + & + \\
\hline & integration & + & - \\
\hline & transparency & + & + \\
\hline & individualization & + & + \\
\hline & professional orientation & + & + \\
\hline & novelty & + & + \\
\hline & problem orientation & - & + \\
\hline & activity & + & + \\
\hline \multirow{4}{*}{ 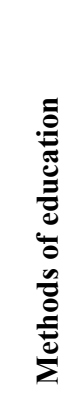 } & $\begin{array}{l}\text { practical (completing various types of practical assignments based on } \\
\text { media materials) }\end{array}$ & + & + \\
\hline & $\begin{array}{l}\text { explanatory-illustrative (presentation of information in the media, } \\
\text { processing and analysis by the audience) }\end{array}$ & - & + \\
\hline & $\begin{array}{l}\text { reproductive (designing and applying a variety of exercises and } \\
\text { assignments using the media to develop problem-solving skills) }\end{array}$ & - & - \\
\hline & $\begin{array}{l}\text { problematic (analysis of problem situations or media texts to develop } \\
\text { critical thinking skills) }\end{array}$ & + & + \\
\hline \multirow{5}{*}{ 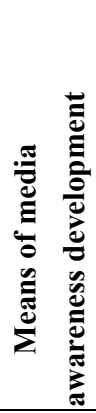 } & $\begin{array}{l}\text { partially exploratory or heuristic (organization of exploratory and } \\
\text { creative activities) }\end{array}$ & + & + \\
\hline & exercises on problematic communicative situations & - & - \\
\hline & $\begin{array}{l}\text { exercises based on the analysis of audio-visual texts (programmes, films, } \\
\text { videos, interviews) }\end{array}$ & + & + \\
\hline & exercises based on illustrative material (photos, drawings, etc.) & + & + \\
\hline & $\begin{array}{l}\text { exercises based on the analysis of texts of different genres, exercises } \\
\text { based on the analysis of feature and documentary films }\end{array}$ & + & - \\
\hline
\end{tabular}

Source: author's development

According to the results provided by the respondents, it is important to note what skills that are necessary for personal media education universities should develop:

- knowledge of different media and the ability to realize their influence regardless of the complexity of media texts;

- ability to distinguish between emotional and proven reaction to related acting; 
- making a competent assumption about the content of the media text;

- awareness of genre diversity and the ability to determine their synthesis;

- ability to critically evaluate media texts regardless of their source (Wan \& Niu, 2018).

It is important to understand that the development of such media literacy skills of future teachers will form a comprehensively developed personality of the future specialist, who is able to effectively use the means of media education to solve academic problems.

For example, the authors of the Digital Competences and Distance Learning in the European Union Report provided information on some best practices introduced to address the pandemic. For example, in Finland, the National Education Agency has long advised schools on the planning and organization of various types of flexible learning, using virtual platforms. In Spain, the Ministry of Education, through the National Institute of Educational Technology and Teacher Education, and in cooperation with the Spanish Radio and Television Corporation, promotes media literacy through material for students on television and online platforms.

In the Czech Republic, public television broadcasts educational programmes for students under the professional guidance of the Ministry of Education, Youth and Sports (Fuster-Guillen, Bardales \& Poma, 2021).

At the same time, Selwyn and Jandric (2020) share their observations of schools in Australia. They claim that no city in this country has a uniform distance learning experience. Moreover, unfortunately, no school would have a unitary form of online learning.

Despite the importance of media literacy, in most Latin American countries, media-oriented education has always been marginalized. It is not included in the curriculum of primary and secondary education, which leads to very little development of experience and reflection, which would be possible to create as long as it has the condition of institutionalization (Garro-Rojas, 2020).

The study of media literacy in online learning in Poland refers to a certain set of skills and abilities. The range of these skills related to the learning process was widely discussed. Besides, it is important to discuss the results of the situation caused by the COVID-19 pandemic and the transition from basic education to distance learning (Cicha et al., 2021). That is, students in their media literacy development should be at a more detailed level to master such areas as:

critical awareness of the impact of the media on individuals and society;

understanding the nature and functioning of the media industry and the characteristics of the media;

analyse the media;

critically evaluate the media;

learn through the media;

express oneself creatively;

be able to control and criticize the media;

practice media ethics;

constructively apply what the media teaches in everyday life (Lee, 2016).

The results of the study showed the need to improve the applied social and communication aspects of media literacy. The anonymous questionnaire provided an opportunity to identify problematic issues in the media literacy development in future specialists in relation to their professional interaction in the learning process, and ways to improve the relevant academic subjects.

There is a need to create special learning environments that can demonstrate the educational potential of the media in addressing typical academic issues. It is necessary to involve students in project activities that provide for the independent use of the media as a means of education. Besides, students should be involved in ongoing activities, including the search, selection and presentation of relevant data needed for effective online and media activities. That is, it is necessary to organize student interactions with all participants in the learning process.

There is also a need to create the space for dialogue needed between teachers and the representative of the media to train specialists who are aware of their responsibilities and obligations to society. The above is able to act as long as the main links that bring together the interests of associations, teachers, universities and information and 
communication professionals, which is the formation of joint networks, to establish the necessary dialogue on media communication, education and media literacy in general.

So, our study provides a new insight into how media education depends on the individual media literacy skills of future specialists. This can be explained by the fact that since relevant knowledge of media literacy should be the main tool to help cope with the high-choice media environment, it is important to emphasize the need for media literacy of future specialists as agents of socialization.

\section{Discussion}

To study the applied social and communication aspects of the media literacy development in future specialists, we took into account different scientific approaches used by the authors in the study of this subject. We suggest to consider some of them.

In the study of applied social and communication technologies, Ostrovska (2017) developed a textbook, which identified all the features of the media literacy development. The author paid the greatest attention to the very concept of applied media literacy and their theoretical approaches (Ostrovska, 2017).

Such scholars as Zavolichna and Zrybnieva (2021) paid much attention to the development of applied social and communicative aspects of media literacy in future teachers. In their research, they emphasize the need for constant development of media literacy and their features (Zavolichna \& Zrybnieva, 2021). The research of Andresen and van den Brink (2013) is also based on determining the relevance of future specialists' media literacy. They investigated how the state of media literacy research is changing, as well as their main characteristics and skills that the future teachers need (Andresen \& van den Brink, 2013).

At the same time, Anders (2018) focuses on improving the professional development and application of future specialists' media literacy. It is worth noting that the study of this issue took into account not only the theoretical aspect, but also a practical one, taking into account current trends (Anders, 2018).

Price et al. (2018) emphasize an important role in the development of media literacy among students of educational institutions who are actually studying in their final years and will soon be able to realize their media literacy in their work. He emphasizes that it is during their studies that students should develop and acquire skills in their media literacy (Price et al., 2018).

In general, Caldeiro-Pedreira and Aguaded-Gómez (2015) state in their study that media literacy is developed to respond to discussions about the interpretation of the media in an out-of-class context involving citizen participation. They draw attention to the fact that media education seeks the formation and development of society, which should adhere to the increasing use of new technologies and new forms of communication, training the recipient in the proper processing of new forms of communication, which contributes to the growth of the state to a more democratic and communicative society (Caldeiro-Pedreira \& Aguaded-Gómez, 2015).

In his research, Garro-Rojas (2020) identifies the priority over media education and focuses on the fact that the media literacy development should be based on the development of pedagogical and educational approaches to media literacy in general.

The scientific works of Zavolichna and Zrybnieva (2021) are also worth mentioning, which considered the media literacy development in a pandemic. They saw the importance of developing media literacy as a factor in adapting to the challenges of the pandemic - as a tool to overcome the panic of the population and as a factor in managerial innovation in the transition to telecommuting. According to them, this will predict development trends and establish the media literacy development, taking into account any factors of pandemic waves (Zavolichna \& Zrybnieva, 2021).

According to Schilder and Redmond (2019), in the spectrum of media literacy it is necessary to define methods in order to move from theoretical references to new spaces of research, which allow studying how media literacy is formed according to their cultural level to understand media in their context (Schilder \& Redmond, 2019).

Martzoukou (2020) notes that there is a unique opportunity to project, develop and implement a sustainable development plan to introduce online education on information skills and digital literacy as a norm, focusing on creating more ways of learning that will be effective for students, and it directly depends on the media literacy development in future specialists. 


\section{Conclusions}

Analysis of applied social and communication aspects of the media literacy development in future specialists is undeniably important for society. The topic of this article attracts the attention of researchers and scholars not only to theoretically consider this topic, but also to provide their recommendations for the media literacy development in future teachers.

The study found that media literacy is fundamental in basic and higher education, which is responsible for providing media education, in which media knowledge is introduced to students from the interpretation they make from the information they need because they spend most of their time on communication in social networks while interacting with several media.

The results of the study showed the need to improve the applied social and communication aspects of media literacy, where there is a need to create special learning environments that can demonstrate the educational potential of the media in addressing typical academic issues. Besides, it was determined that it is necessary to involve students in project activities that provide for the independent use of the media as a means of education; and students should be involved in ongoing activities, including the exploring, selection and presentation of relevant data needed for effective online and media activities. So, it is necessary to arrange student interactions with all participants in the learning process.

Moreover, there is a need to expand the dialogue needed between learners, teachers and media professionals to train specialists who are aware of their responsibilities and obligations to society. This is important until the main links that bring together the interests of associations, teachers, universities, as well as information and communication professionals, which is the formation of joint networks, establish the necessary dialogue on media communication, education and media literacy in general.

The results obtained during the study can be used in research, law-making, law enforcement and educational process. For example, research activities provide an opportunity to continue the theoretical search to improve the applied social and communication aspects of the media literacy development in future specialists. It is necessary to take into account the results obtained in law-making, because proposals were formulated to improve the media literacy development in future teachers. Application in law enforcement will provide an opportunity to improve the practice of applied social and communication aspects of the media literacy development in future specialists, and increase its efficiency. The use of this study in the educational process is no less important, as the results of the study can be used in conducting classes in educational institutions that involve the study of subjects exploring this issue.

\section{References}

Akimov, O., Karpa, M., Parkhomenko-Kutsevil, O., Kupriichuk, V., \& Omarov, A. (2021). Entrepreneurship education of the formation of the e-commerce managers professional qualities. International Journal of Entrepreneurship, 25(7), 1-8.

Anders, A. (2018). Networked learning with professionals boosts students' self-efficacy for social networking and $\begin{array}{llllll}\text { professional development. } \quad \text { Computers } \quad \& \quad \text { Education, } & 127, & 13-29 .\end{array}$ https://doi.org/10.1016/j.compedu.2018.08.009.

Andresen, B., \& van den Brink, K. (2013). "Multimedia in Education" Curriculum. Paris: UNESCO Institute for Information Technologies in Education.

Area Moreira, M., Borrás Machado, J. F., \& San Nicolás Santos, M. B. (2015). Educating the millennial generation as cultured citizens of cyberspace: Notes for digital literacy. Revista de Estudios de Juventud, 109, 13-32.

Caldeiro-Pedreira, M. C., \& Aguaded-Gómez, J. I. (2015). Communicative literacy and media competence in the hypercommunicated society. Revista Digital De Investigación en Docencia Universitaria, 9(1), 37-56. https://doi.org/10.19083/ridu.9.379

Cicha, K., Rutecka, P., Rizun, M., \& Strzelecki, A. (2021). Digital and media literacies in the Polish education system-pre-and post-COVID-19 perspective. Education Sciences, 11(9), 532. https://doi.org/10.3390/educsci11090532

Cuervo Sánchez, S. L., \& Medrano Samaniego, C. (2014). Media literacy: Beyond competency development. Teoría de la Educación. Revista Interuniversitaria, 25(2), 111-131. https://doi.org/10.14201/11577 
de Pablos Pons, J., \& Ballesta Pagán, J. (2018). Media education in our environment: Realities and possible improvements. Revista Interuniversitaria de Formación del Profesorado, 32(91), 117-132.

Fuster-Guillen, D., Bardales, H., \& Poma, T. (2021). Media literacy: a necessity in basic and university education. Laplage em Revista, 7(3C), 1-18. https://doi.org/10.24115/S2446-6220202173C1499p.1-18

Garro-Rojas, L. (2020). Media literacy in Latin America: Issues and experiences. Revista Educación, 44(1), 1-22. https://doi.org/10.15517/revedu.v44i1.37708

Jandrić, P. (2019). The postdigital challenge of critical media literacy. The International Journal of Critical Media Literacy, 1(1), 26-37. https://doi.org/10.1163/25900110-00101002

Jones-Kellogg, R. L., \& Martin, S. (2018). Portuguese as a world language for future army officers. Hispania, 100(5), 295-296. https://doi.org/10.1353/hpn.2018.0071

Kühn, J., \& Riesmeyer, C. (2021). Media literacy as precondition for media-pedagogical teaching practices? An empirical study. Retrieved from https://www.researchgate.net/publication/354628349_Media_Literacy_as_Precondition_for_Media-Pedagogical _Teaching_Practices_An_Empirical_Study

Lee, A. Y. L. (2016). Media education in the School 2.0 era: Teaching media literacy through laptop computers and iPads. Global Media and China, 1(4), 435-449. https://doi.org/10.1177/2059436416667129

Livingstone, S., \& Sefton-Green, J. (2016). The class. In the class. New York: New York University Press.

Martzoukou, K. (2020). Academic libraries in COVID-19: A renewed misión for digital literacy. Library Management, 42(4/5), 266-276. https://doi.org/10.1108/LM-09-2020-0131

Mertala, P. (2020). Misunderstanding child-centeredness: The case of "child 2.0" and media education. Journal of Media Literacy Education, 12(1), 26-41. https://doi.org/10.23860/JMLE2020- 12-1-3

Ostrovska, N. V. (2017). Applied social and communication technologies. Zaporizhzhia: ZNTU.

PARP. (2020). Digital competences and distance learning in the European Union. Warszawa: PARP.

Pérez-Escoda, A. (2017). Media competence, ICT and digital skills. Torrossa. Retrieved from https://www.torrossa.com/en/resources/an/4229940

Price, A. M., Devis, K., LeMoine, G., Crouch, S., South, N., \& Hossain, R. (2018). First year nursing students use of social media within education: Results of a survey. Nurse Education Today, 61, 70-76. https://doi.org/10.1016/j.nedt.2017.10.013

Schilder, E., \& Redmond, T. (2019). Measuring media literacy inquiry in higher education: Innovation in assessment. Journal of Media Literacy Education, 11(2), 95-121. https://doi.org/10.23860/JMLE-2019-11-2-6.

Selwyn, N., \& Jandric, P. (2020). Postdigital living in the age of Covid-19: Unsettling what we see as possible. Postdigital Science and Education, 2, 989-1005. https://doi.org/10.1007/s42438-020-00166-9

Semenova, Y., \& Sotnikova, S. (2021). Developing media literacy skills of future specialists in the contemporary teacher training education. SHS Web of Conferences 97, 01033. https://doi.org/10.1051/shsconf/20219701033

Sharikov, A. V., Fazulyanova, S. N., \& Petrushkina, E. V. (2006). Towards the harmonization of media and society (media resources and media education in secondary schools of Samara) stimulus No. 8. Samara: SNTU.

Wan, S., \& Niu, Z. (2018). An e-learning recommendation approach based on the selforganization of learning resource. Knowledge-Based Systems, 160, 71-81.

Zavolichna, T., \& Zrybnieva, I. (2021). Trends in innovative management decisions: the role of media literacy in overcoming the challenges of the pandemic. German Science Herald, 2, 11-14.

\section{Copyrights}

Copyright for this article is retained by the author(s), with first publication rights granted to the journal.

This is an open-access article distributed under the terms and conditions of the Creative Commons Attribution license (http://creativecommons.org/licenses/by/4.0/). 